\title{
QNREL
}
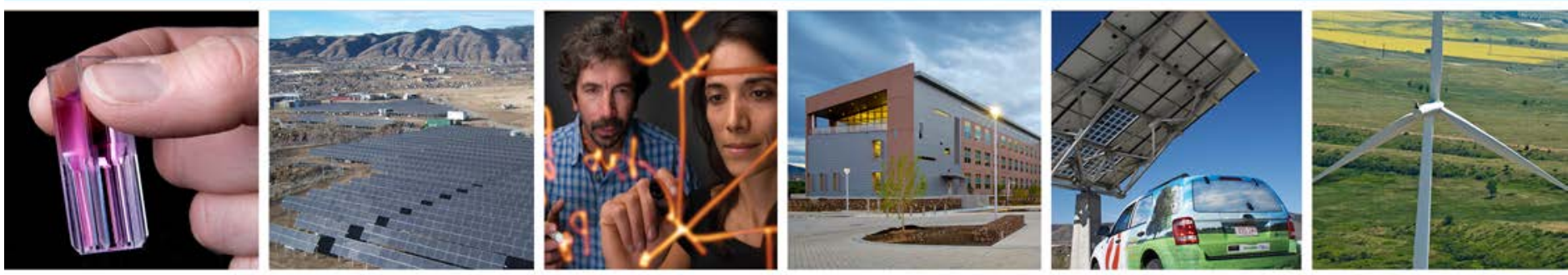

\section{Integrating High Penetrations of PV into Southern California: Year 2 Project Update}

\section{Preprint}

Barry Mather

National Renewable Energy Laboratory

Russell Neal

Southern California Edison

Presented at the 2012 IEEE Photovoltaic Specialists Conference Austin, Texas

June 3-8, 2012

NREL is a national laboratory of the U.S. Department of Energy, Office of Energy

Efficiency \& Renewable Energy, operated by the Alliance for Sustainable Energy, LLC.

Conference Paper

NREL/CP-5500-54131

August 2012

Contract No. DE-AC36-08GO28308 


\section{NOTICE}

The submitted manuscript has been offered by an employee of the Alliance for Sustainable Energy, LLC (Alliance), a contractor of the US Government under Contract No. DE-AC36-08GO28308. Accordingly, the US Government and Alliance retain a nonexclusive royalty-free license to publish or reproduce the published form of this contribution, or allow others to do so, for US Government purposes.

This report was prepared as an account of work sponsored by an agency of the United States government. Neither the United States government nor any agency thereof, nor any of their employees, makes any warranty, express or implied, or assumes any legal liability or responsibility for the accuracy, completeness, or usefulness of any information, apparatus, product, or process disclosed, or represents that its use would not infringe privately owned rights. Reference herein to any specific commercial product, process, or service by trade name, trademark, manufacturer, or otherwise does not necessarily constitute or imply its endorsement, recommendation, or favoring by the United States government or any agency thereof. The views and opinions of authors expressed herein do not necessarily state or reflect those of the United States government or any agency thereof.

Available electronically at http://www.osti.gov/bridge

Available for a processing fee to U.S. Department of Energy and its contractors, in paper, from:

U.S. Department of Energy

Office of Scientific and Technical Information

P.O. Box 62

Oak Ridge, TN 37831-0062

phone: 865.576.8401

fax: 865.576 .5728

email: mailto:reports@adonis.osti.gov

Available for sale to the public, in paper, from:

U.S. Department of Commerce

National Technical Information Service

5285 Port Royal Road

Springfield, VA 22161

phone: 800.553 .6847

fax: 703.605.6900

email: orders@ntis.fedworld.gov

online ordering: http://www.ntis.gov/help/ordermethods.aspx

Cover Photos: (left to right) PIX 16416, PIX 17423, PIX 16560, PIX 17613, PIX 17436, PIX 17721

Printed on paper containing at least $50 \%$ wastepaper, including $10 \%$ post consumer waste. 


\title{
Integrating High Penetrations of PV into Southern California: Year 2 Project Update
}

\author{
Barry Mather $^{1}$ and Russell Neal ${ }^{2}$ \\ ${ }^{1}$ National Renewable Energy Laboratory, Golden, CO 80401, USA, ${ }^{2}$ Southern California Edison, \\ Westminster, CA, 92683
}

\begin{abstract}
Southern California Edison (SCE) is well into a five-year project to install a total of $500 \mathrm{MW}$ of distributed photovoltaic (PV) energy within its utility service territory. Typical installations to date are 1-3 $\mathrm{MW}_{\text {peak }}$ rooftop PV systems that interconnect to medium-voltage urban distribution circuits or larger $\left(5 \mathrm{MW}_{\text {peak }}\right)$ ground-mounted systems that connect to medium-voltage rural distribution circuits. Some of the PV system interconnections have resulted in distribution circuits that have a significant amount of $P V$ generation compared to customer load, resulting in high-penetration PV integration scenarios. The National Renewable Energy Laboratory (NREL) and SCE have assembled a team of distribution modeling, resource assessment, and PV inverter technology experts in order to investigate a few of the high-penetration PV distribution circuits. Currently, the distribution circuits being studied include an urban circuit with a PV penetration of approximately $46 \%$ and a rural circuit with a PV penetration of approximately $60 \%$. In both cases, power flow on the circuit reverses direction, compared to traditional circuit operation, during periods of high $P V$ power production and low circuit loading. Research efforts during year two of the five-year project were focused on modeling the distribution system level impacts of highpenetration PV integrations, the development and installation of distribution circuit data acquisition equipment appropriate for quantifying the impacts of high-penetration PV integrations, and investigating high-penetration PV impact mitigation strategies. This paper outlines these research efforts and discusses the following activities in more detail: the development of a quasistatic time-series test feeder for evaluating high-penetration PV integration modeling tools; the advanced inverter functions being investigated for deployment in the project's field demonstration and a power hardware-in-loop test of a $500-\mathrm{kW}$ PV inverter implementing a limited set of advanced inverter functions.
\end{abstract}

Index Terms - high-penetration PV integration, PV impact, distribution system, power hardware-in-loop testing, PHIL

\section{INTRODUCTION}

The Southern California Edison (SCE) High-Penetration PV (HPPV) Integration Project is a five-year study aiming to develop distribution planning best practices for integrating large commercial/utility-scale PV systems into the distribution system with minimal operational and cost impact to the distribution system operator and the PV system developer. The National Renewable Energy Laboratory (NREL), Southern California Edison (SCE), Quanta Technology, Satcon Technology Corporation, Electrical Distribution Design (EDD), and Clean Power Research (CPR) have teamed together on the project to analyze and quantify the impacts of high-penetration levels of photovoltaic (PV) resources interconnected with the SCE distribution system. Specifically, SCE will be interconnecting a total of 500 MW of commercial-scale PV by 2015 within their service territory through a program approved in 2010 by the California Public Utility Commission (CPUC). More details are given on the status of SCE's PV deployment in Section II.

A report that covers the project's first-year efforts and findings is available [1]. Following the findings of this report, specific tasks were planned to begin to identify and quantify the impacts of interconnected PV systems on the distribution system level. The tasks undertaken are divided into the following three categories:

- Modeling and simulation of distribution circuits to identify and quantify the impacts of high-penetration PV integration

- Development of advanced functionality inverters with functions useful in mitigating the impacts of highpenetration PV integration

- Laboratory testing of advanced functionality inverters to determine the effectiveness of PV impact mitigation strategies

Under the modeling and simulation task heading, multiple efforts were commenced under the project. The development of PV resource datasets of the appropriate temporal and spatial resolution are under development. Additionally, methods for completing high-penetration PV integration studies are being developed for the current state-of-the-art PV inverter technologies. A report, to be completed later this year, will investigate the usefulness of quasi-static time-series simulation for accurately modeling some low-bandwidth dynamics of the distribution system such as capacitor bank switching, load variability etc. Finally, a quasi-static timeseries test feeder based was developed as a testing and evaluation platform for high-penetration PV integration analysis. A report on the developed test case will be published at the upcoming IEEE Power and Energy Society (PES) General Meeting in July 2012 [2] and is described in Section III.

The development of advanced-functionality inverters is ongoing. Current development efforts include refining the Volt/VAr characteristics that may be effective in mitigating some of the PV impacts on an interconnected distribution system. Details on this effort are briefly covered in Section IV.

Laboratory testing of a $500-\mathrm{kW}$ PV inverter was undertaken as a joint effort between the SCE High-Penetration PV Integration Project, Southern California Edison, and the Florida State University (FSU) Center for Advanced Power Systems (CAPS), specifically the Sunshine State Solar Grid 
Initiative (SUNGRIN). The laboratory testing of the large PV inverter is described in Section V.

\section{Status of High-Penetration PV DePloyment at SCE}

Interest in the integration of $\mathrm{PV}$ on the distribution grid continues to increase as the amount of deployed distribution interconnected PV within utility service territories increases. Predictably, when considering the first few commercial/utilityscale PV system interconnections, the locations within a utility service territory that afford the easiest interconnections (most likely causing the least impact to the local distribution system) are exercised first. As PV deployment continues, there is everincreasing pressure to integrate $\mathrm{PV}$ onto the distribution system at locations that are of higher impact as the locations of easier interconnection are exhausted. In some service territories and at some level of distribution system impact, a limit on the amount of PV that can be integrated into a local distribution system may be reached, effectively barring additional PV system interconnections in that area.

SCE has currently deployed $71 \mathrm{MW}$ of the total planned 500 MW of distribution system interconnected PV within its service territory [3] under the Solar PV Project (SPVP). Additionally, SCE had originally proposed installing $250 \mathrm{MW}$ of PV itself and purchasing the power output of an additional $250 \mathrm{MW}$ of PV from independent power producers (IPP). SCE requested, from the California Public Utility Commission (CPUC), that the utility-owned PV generation portion of the total 500-MW build-out be lowered to $125 \mathrm{MW}$. In this case the IPP share would be increased to $375 \mathrm{MW}$, leaving the overall PV build-out rating of $500 \mathrm{MW}$ the same but with a different ownership model. SCE has also requested that a greater share of the deployed PV systems be ground-mounted types as opposed to roof-mounted PV systems.

Overall, the PV deployment under the SPVP is progressing smoothly, with the greatest challenges being management of the large interconnection request queue and managing the interconnection study process when multiple interconnections are requested on the same or adjacent distribution feeders. In these cases it becomes difficult to complete an accurate PV impact study of the system as the deployed PV on the system is largely unknown due to the fact that many PV interconnections are not exercised even when approved due to changing economic and financial circumstances of the PV developers. In short, the engineers completing the interconnection studies are trying to analyze a system whose basic system level attributes are in flux.

SCE's experience with high penetration is considerable for a North American utility. Other utilities around the world as reported in [4] are also gaining experience with high penetrations of $\mathrm{PV}$ in their systems.

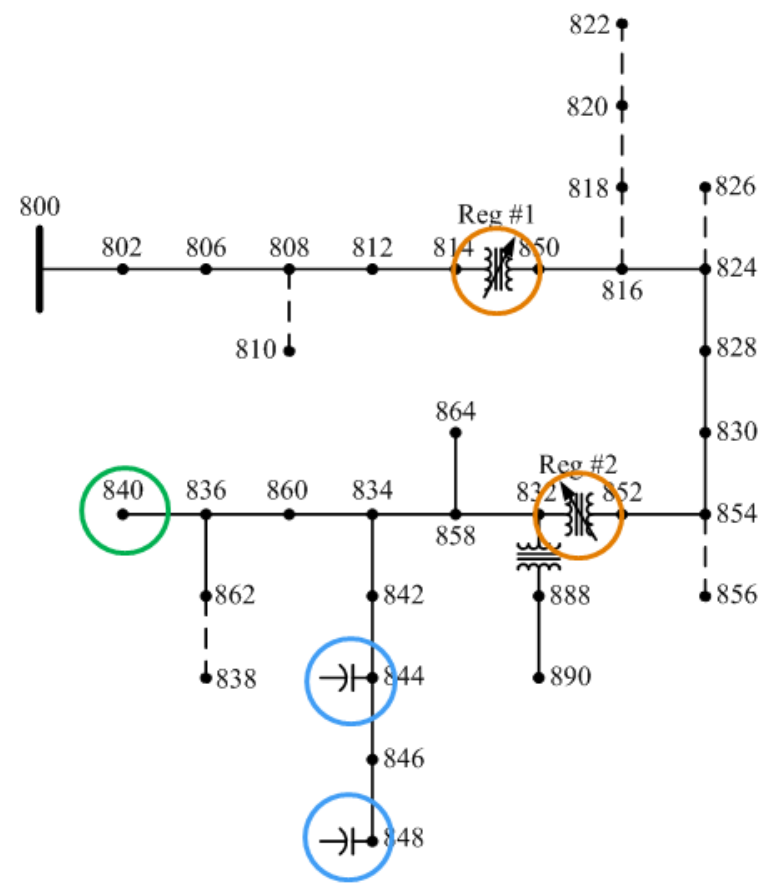

Fig. 1. One-line diagram of the IEEE 34 node test feeder highlighting the actively controlled voltage regulators (orange), the fixed capacitors (blue), and the point of common coupling for the analysis presented at the end of the circuit (green).

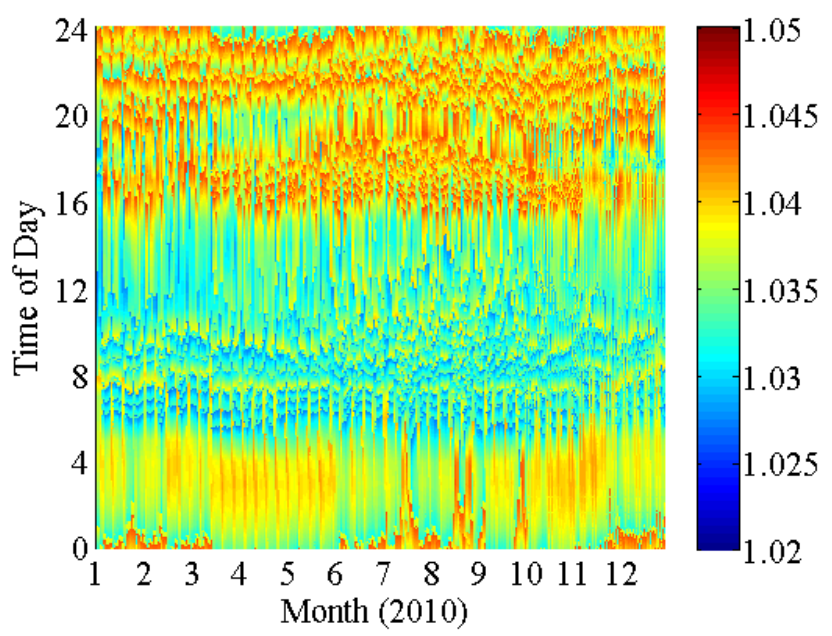

Fig. 2. Phase A per unit voltage at the end of the circuit (node 840) for operation during an entire year (2010) with no PV interconnected onto the circuit. 


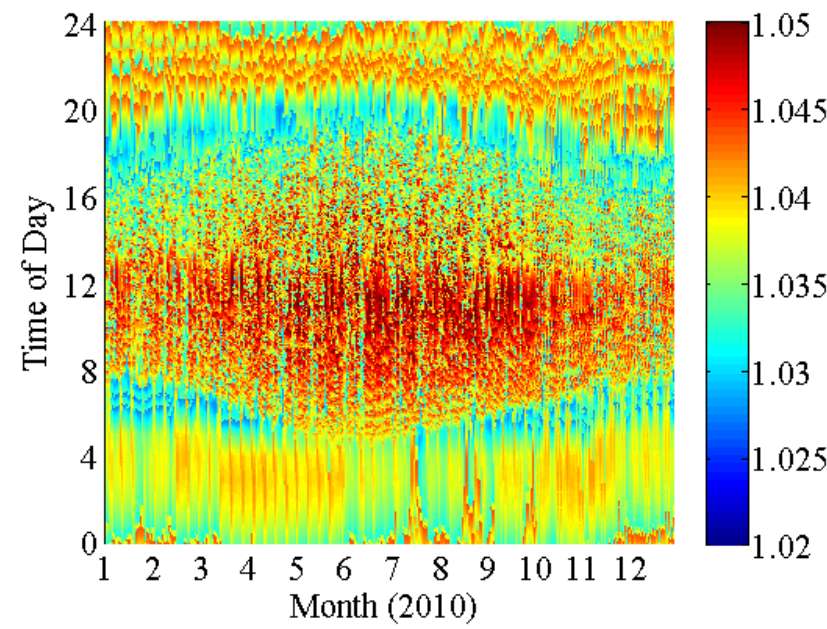

Fig. 3. Phase A per unit voltage at the end of the circuit (node 840) for operation during an entire year (2010) with a 2-MW PV plant interconnected at the end of the circuit (node 840).

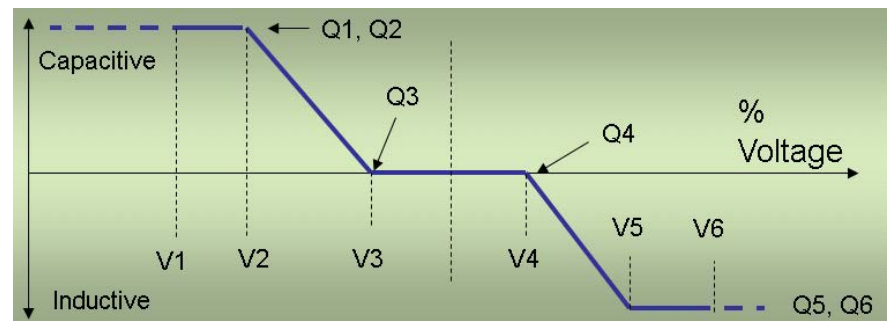

Fig. 4. Diagram showing a piecewise linear operating mode for VAr output based on point of common coupling voltage that may be implemented to mitigate the effects of high-penetration PV integration.

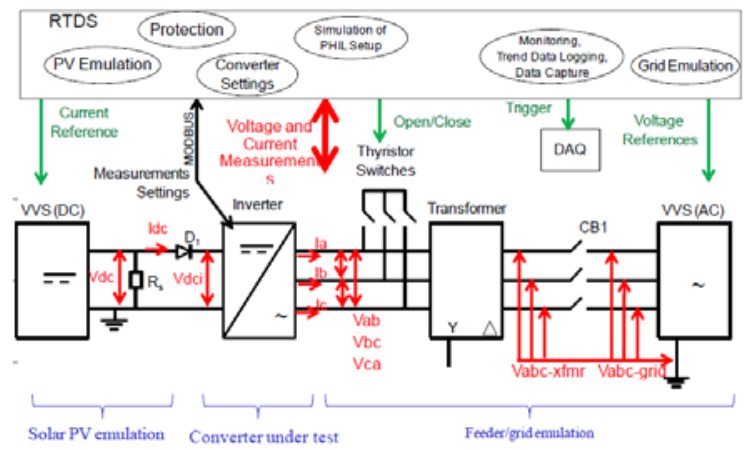

Fig. 5. Diagram showing the basic setup of the power hardware-inloop (PHIL) PV inverter test. The thyristor switches and circuit breaker CB1 were not used during the PHIL tests but were used for previously conducted steady-state testing.

\section{DeVelopment of a Quasi-STATIC TIME-SERIES Test CASE FOR EVALUATING THE IMPACT OF HIGH-PENETRATION PV INTEGRATION AND THE EFFECTIVENESS OF IMPACT Mitigation MEASURES}

Quasi-static time-series simulation of distribution circuits has traditionally been used to determine the low-frequency dynamic operational characteristics of a distribution circuit containing low bandwidth voltage control equipment such as switched capacitor banks, load tap changers (LTCs), and inline voltage regulators (VRs). These pieces of equipment operate at very low bandwidths compared to the time it takes for a perturbation of the distribution system to effectively settle out within the distribution system. Due to this fact, quasi-static time-series simulation at discrete time intervals around the effective control bandwidth of the fastest automatic voltage regulation equipment is an effective way of evaluating the operation of a distribution circuit over time. The quasistatic time-series test feeder was developed to be used as a tool and platform for benchmarking PV interconnection studies and the resulting PV impact mitigation solutions. The test feeder case is based on the IEEE 34 node test feeder [5] that includes two inline voltage regulators. The IEEE 34 node test feeder is shown in Fig. 1. While the systems under investigation within the SCE service territory do not employ inline voltage regulators, many utilities do use these devices regularly. This is particularly true on long rural circuits where the impedance of the line is significant due to the length of the circuit. The test feeder case uses data inputs for the circuit loading and PV resource that are both publically available. A detailed paper describing the quasi-static time-series test feeder will be published in the proceedings of the IEEE PES General Meeting in July 2012 [2].

Using the test feeder developed under the SCE HPPV Integration Project, it is easy to investigate a wide range of PV impacts caused by large PV systems. In Fig. 1, node 840 is circled in green and has been used as the point of interconnection for much analysis related to PV impacts and mitigation. For instance, the impact of the point of interconnection voltage for a 2-MW PV system interconnected at the end of the circuit (node 840) can be evaluated by inspection of Figs. 2 and 3. Fig. 2 shows the phase A per unit voltage at node 840 for every minute of the test year (2010) for the base case, i.e. when no PV systems are interconnected on the circuit. Note: per unit voltages are referred to the primary, so all the voltages shown are above 1 p.u. to compensate for voltage drop in the secondary circuit. The perunit voltage magnitude is plotted by color (blue denoting lower voltage, red denoting higher voltage). Fig. 2 shows that the voltage at node 840 normally stays within a relatively tight range. The voltage regulators are actively operating as the load on the circuit shifts due to changes in load during the day. Fig. 3 shows the same phase A voltage at node 840, but for the case when a 2-MW PV system is interconnected. The expected voltage rise at the point of interconnection is clearly shown as a football-shaped region centered on the middle of the day and widest during the summer when sun angles result 
in the most PV power production. The added voltage fluctuations can also be seen as the color changes during a day (on a vertical line trajectory), sometimes showing dark red colors denoting high voltage and lighter yellow or blue voltages during the next instance.

\section{VOLT/VAR PV INVERTER CAPABILITY}

As part of the project, an advanced-capability PV inverter will be installed in the SCE distribution system on one of the study feeders. In order to prepare for this field demonstration, multiple advanced inverter functions are being developed. All the advanced inverter functions are designed to mitigate or reduce the effects of high-penetration PV integration on the distribution circuits. Many advanced inverter functions have been proposed by utilities, consultants, and developers and are described in [6]. In this project we are currently focusing on a limited set of Volt/VAr control methods that do not require active utility control. Such control requires robust communications channels as well as an active operator. Largely independent mitigation methods that require only set points from the operating utility, perhaps only seasonally or perhaps only when a major circuit modification occurs, require a less robust communications channel and do not burden the operating utility with making regular control decisions. Along with constant power factor (PF) control and constant VAr set point control, Fig. 4 shows one of the desired Volt/VAr control methods. Given the set points Q1 through Q6 and V1 though V6, nearly any desired piecewise linear relationship between the point of common coupling voltage seen by the PV inverter and its VAr output set point can be implemented for Volt/VAr mitigation strategies.

Additionally, further refinements have been made to determine Volt/VAr modes of operation for situations when the PV inverter could produce more real power output but the VAr or PF settings limit such output due to the current rating of the inverter. In these cases, control modes that "fold-back" the PF or VAr set point are often desirable in order to provide as much PV impact mitigation as possible but also not curtail—even for short periods of time - any realizable real power generation. From a PV impact mitigation point of view, these modes may not make sense as the VArs being supplied are seen as the required level of VArs in order to mitigate the real power generation impact. Studies and tests have been undertaken to investigate both the "fold-back" modes and the "non-fold-back" modes to determine the differences in operation on the impacts of PV interconnection on the distribution system.

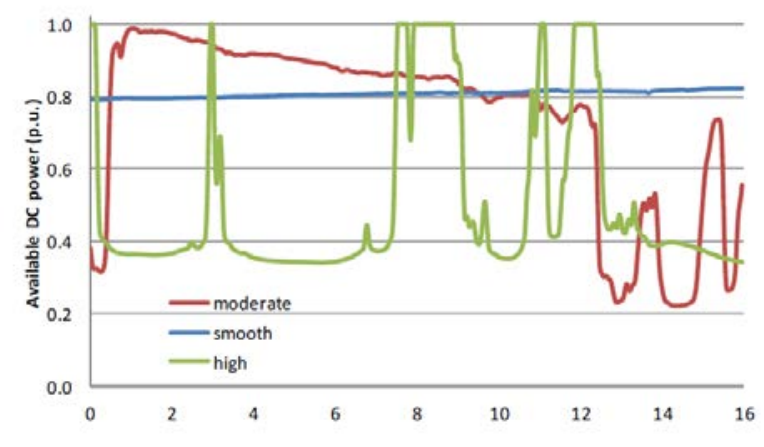

Fig. 6. Sixteen-minute-long PV power profiles used during PHIL tests. Profiles had a temporal resolution of 2 seconds.
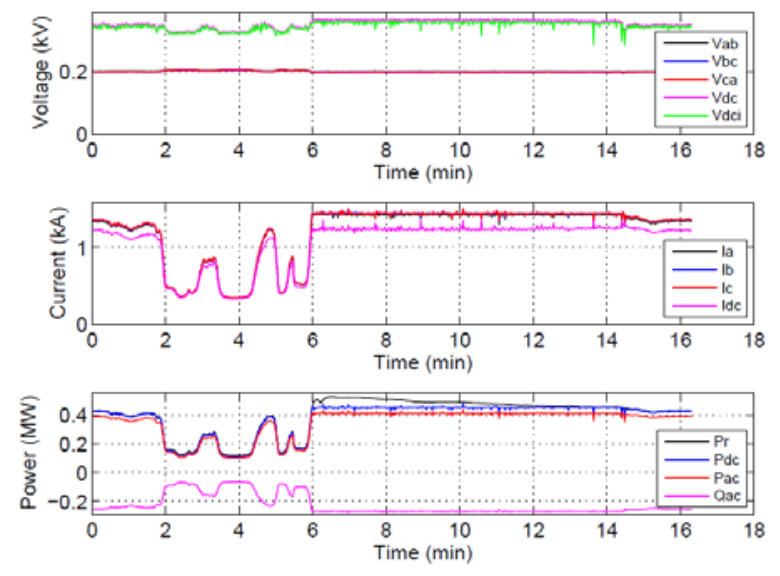

Fig. 7. Example strip-chart like output from the PHIL tests for the interconnection of a 500-kW PV inverter on the Fontana, California, study feeder operating at a power factor of 0.85 lagging.

\section{POWER HARDWARE-IN-LOOP (PHIL) TESTING OF A 500- KW PV INVERTER}

The laboratory testing undertaken at the Florida State University (FSU) Center for Advanced Power Systems (CAPS) as part of the SCE HPPV Integration Project had the following three primary objectives:

- Demonstrate and evaluate the ability of a large PV inverter to implement a limited set of advanced inverter functions

- Analyze how effective certain advanced inverter functions are at mitigating the impacts of highpenetration PV integration

- Advance the state-of-the-art practice in power hardware-in-loop (PHIL) PV inverter testing

All three objectives were met following a week of testing in March 2012. The PHIL PV inverter testing included the complete emulation of both the $\mathrm{DC}$ and $\mathrm{AC}$ connections to a $500-\mathrm{kW}$ PV inverter. The DC PV array was emulated using a Real-Time Digital Simulator (RTDS) and allowed the PV 
inverter to operate in a fully operation maximum peak power tracking mode for all the tests completed. The I-V characteristics of the emulated PV array could be adjusted to effectively adjust the available DC power (peak power point) to the inverter DC terminals. The three-phase grid connection to the PV inverter was also fully emulated via RTDS and a three-phase variable voltage supply. Fig. 5 shows the connections of the PV inverter under test with the DC and AC variable voltage sources. The role of the RTDS is also shown. The RTDS was used for DC and AC connection emulation, data acquisition, and safety controls. This is the first test of its kind that includes full DC and AC grid connection emulation. The goal of testing in this manner was to effectively test the PV inverter in a real-world system. For this case the emulated grid to which the inverter was "connected" via PHIL testing was the Fontana study feeder described in [2]. A full RSCAD model of the feeder was implemented within the RTDS framework. By implementing the study feeder in the RTDS it was possible to collect data from all feeder nodes during the tests completed, allowing for the investigation of the complete PV impacts on the entire circuit caused by a single PV system interconnection.

The tests conducted consisted of sixteen-minute-long periods of emulated circuit operation. Three different PV profiles with varying variability were used during the tests. These profiles are shown in Fig. 6 . The feeder loading profile for all tests was derived from measured loading data for the Fontana, California, study feeder.

Fig. 7 shows a graph of the testing output resulting from one of the sixteen-minute test runs. In this case the $500-\mathrm{kW}$ inverter was interconnected to the Fontana, California, study feeder at the same location that a PV system presently exists in the actual circuit. The power factor (PF) set point for the test run shown was 0.85 inductive. Upon examination one can see that the real and reactive power move in concert but in opposite directions as the available DC power from the emulated PV array varies. This is the expected behavior for constant power factor operation. Small variations in the PV inverter output voltage (200 $\mathrm{V}_{\mathrm{ac}, \text { rms }}$ base) can also be seen as the available PV array power varies. These changes are small as the PV inverter is interconnected fairly close to the substation in this simulation so that the circuit voltage at the point of interconnection is fairly stiff. Nonetheless, the data has been collected and will be analyzed to quantify the impacts of high-penetration PV integration on the simulated circuit. The findings of the described PHIL testing will be compared with actual data collected on the study feeder to see if the PHIL PV inverter testing correctly emulated the PV impacts.

\section{CONCLUSION}

The National Renewable Energy Laboratory (NREL), Southern California Edison (SCE), Quanta Technology, Satcon Technology Corporation, Electrical Distribution Design (EDD), and Clean Power Research (CPR) continue to make progress toward developing best practices for integrating commercial/utility-scale PV systems on the distribution system. A number of efforts under this project were discussed, including the development of a quasi-static time-series test feeder for use in evaluating PV impact study tools and mitigation measures. The advanced PV inverter functions being investigated and implemented in real PV inverter hardware were briefly described, and a recent testing effort including the first of its kind power hardware-in-loop (PHIL) of a PV inverter, effectively emulating the complete interconnection of the PV inverter in one of the study feeder circuits included in the study, was discussed.

\section{ACKNOWLEDGEMENT}

The SCE High-Penetration PV Integration Project is supported by the U.S. Dept. of Energy (DOE) Office of Energy Efficiency and Renewable Energy (EERE), Solar Energy Technologies Program (SETP), under the Analysis of High Penetration Levels of PV into the Distribution Grid in California Project, award no. DE-EE0002061, with match funding from the California Public Utility Commission (CPUC) California Solar Initiative (CSI) Research, Development, Demonstration and Deployment (RD\&D). SCE also supports the project as the host utility.

\section{REFERENCES}

[1] B. Mather et al., "Southern California Edison High-Penetration Photovoltaic Project - Year 1," NREL Technical Report: TP5500-50875, 2011.

[2] B. Mather, "Quasi-static time-series test feeder for PV integration analysis on distribution systems," accepted to the IEEE Power and Energy Society General Meeting, Austin, TX, 2012.

[3] G. D. Rodriguez, "SCE Experience with PV Integration," proc. of SEPA/EPRI/DOE/SNL/NREL High-Penetration PV Grid Integration Workshop, April $28^{\text {th }}, 2012$, available online at: http://www.solarelectricpower.org/events/utility-solarconference/usc-home.aspx\#tabWorkshop.

[4] B. Braun et al., "Is the distribution grid ready to accept large scale photovoltaic deployment? - State of the art, progress and future prospects," Prog. Photovolt: Res. Appl., Nov. 2011.

[5] Distribution System Analysis Subcommittee of the IEEE Power Engineering Society, IEEE 34 Node Test Feeder, online resource: http://www.ewh.ieee.org/soc/pes/dsacom/testfeeders/ index.html.

[6] J.W. Smith, W. Sunderman, R. Dugan and B. Seal, "Smart inverter Volt/VAr control functions for high penetration of PV on distribution systems," in proc. of the IEEE/PES Power Systems Conference and Exposition, 2011. 